\title{
Prenatal exposure to serotonin reuptake inhibitors and congenital heart anomalies: an exploratory pharmacogenetics study
}

\begin{abstract}
Aim: To explore the role of pharmacogenetics in determining the risk of congenital heart anomalies (CHA) with prenatal use of serotonin reuptake inhibitors. Methods: We included 33 case-mother dyads and 2 mother-only (child deceased) cases of $\mathrm{CHA}$ in a case-only study. Ten genes important in determining fetal exposure to serotonin reuptake inhibitors were examined: CYP1A2, CYP2C9, CYP2C19, CYP2D6, $A B C B 1$, SLC6A4, HTR1A, HTR1B, HTR2A and HTR3B. Results: Among the exposed cases, polymorphisms that tended to be associated with an increased risk of CHA were SLC6A4 5-HTTLPR and 5-HTTVNTR, HTR1A rs1364043, HTR1B rs6296 and rs6298 and HTR3B rs1176744, but none reached statistical significance due to our limited sample sizes. Conclusion: We identified several polymorphisms that might potentially affect the risk of $\mathrm{CHA}$ among exposed fetuses, which warrants further investigation.
\end{abstract}

First draft submitted: 26 February 2017; Accepted for publication: 2 May 2017; Published online: 22 June 2017

Keywords: gene-environment interaction $\bullet$ heart defects $\bullet$ pharmacogenetics $\bullet$ serotonin reuptake inhibitors $\bullet$ teratogenicity

One of the most prescribed antidepressant groups is the selective serotonin reuptake inhibitors (SSRIs), with up to 4 in 100 pregnant women being prescribed with this group of antidepressants [1-3]. SSRIs are generally well tolerated with the exception of concerns about increased risk of fetal congenital anomalies following prenatal exposure to these drugs. Following the US FDA warning about this risk in 2005, many studies have been performed to elucidate the magnitude and effect of this association. However, the results of these studies have been inconsistent. Meta-analyses by two groups of researchers reported around a $40 \%$ increase in the risk of fetal congenital heart anomalies (CHA) following prenatal exposure to paroxetine [4-6], but a similar risk increment was not found for all the SSRIs combined [7]. Because clinical trials are not an option for measuring the risk of an exposure during pregnancy, most studies were done retrospectively using data from pregnancy and/or prescription registries. The conflicting study results in impede decision-making among clinicians on a safe and effective therapy for their patients, and best practice at present is to assess individual risk factors before any treatment recommendation.

We previously identified several genes that might be important in the metabolism and mechanism of action of SRIs that may also potentially play a role in the development of SRI-related CHA [8]. Several polymorphisms of metabolic enzymes (CYP1A2, CYP2C9, CYPC19 and CYP2D6) were reported to affect the pharmacokinetics and the risk of side effects of SRIs $[9,10]$. $\mathrm{P}$-glycoprotein (P-gp) expressed in the placenta plays a role in limiting fetal exposure to SRIs, and several SNPs were found to reduce P-gp function [11]. In addition, a number of polymorphisms of the serotonin
Aizati N A Daud ${ }^{* 1,2}$, Jorieke E H Bergman ${ }^{3}$, Wilhelmina S Kerstjens-Frederikse ${ }^{3}$, Pieter van der Vlies ${ }^{3}$, Eelko Hak', Rolf M F Berger ${ }^{4}$, Henk Groen $^{5}$ \& Bob Wilffert ${ }^{1,6}$

${ }^{1}$ Unit of PharmacoTherapy, -Epidemiology \& -Economics, Department of Pharmacy, University of Groningen, Groningen Research Institute of Pharmacy, Groningen, The Netherlands

${ }^{2}$ School of Pharmaceutical Sciences, Universiti Sains Malaysia, Penang, Malaysia

${ }^{3}$ Department of Genetics, University of Groningen, University Medical Center Groningen, Groningen, The Netherlands ${ }^{4}$ Department of Pediatric Cardiology، University of Groningen, University Medical Centre Groningen, Groningen The Netherlands

${ }^{5}$ Department of Epidemiology, University of Groningen, University Medical Centre Groningen, Groningen, The Netherlands ${ }^{6}$ Department of Clinical Pharmacy \& Pharmacology, University of Groningen, University Medical Center Groningen, Groningen, The Netherlands

*Author for correspondence: aizati.daud@gmail.com 
transporter (SERT) and the serotonin receptor genes were associated with variation in the clinical response to SRIs and the severity of side effects [12-14].

We therefore aimed to explore the genetic variations that may be involved in fetal exposure to SRIs, and their mechanism of action, to further understand why some children exposed to SRIs in the first trimester of pregnancy develop CHA while others do not. Our objective was to determine the effect of the gene $x$ environment $(G \times E)$ interaction between pharmacogenetic predictors of the SRIs and prenatal exposure to these drugs on the risk of CHA.

\section{Methods}

Study design

We performed an exploratory $\mathrm{G} \times \mathrm{E}$ interaction study using case-only design. This design can detect the effect of genotype and exposure in a group of cases when the disease is rare. In our case, we considered $\mathrm{CHA}$ as a relatively rare disease, and $\mathrm{G} \times \mathrm{E}$ interaction studies have been commonly performed to investigate the genetic and environmental risk factors for congenital anomalies. One of the assumptions made is that the genotype and environment are independent of each other [15-17].

\section{Patient sampling}

The study population includes children with CHA registered in the EUROCAT Northern Netherlands (NNL) database, a population-based birth defect registry covering the three northern provinces of The Netherlands. EUROCAT NNL registers fetuses or children diagnosed with major congenital anomalies before or after birth, and up to 10 years old, upon consent of their parents. For cases registered up to 2001, the types of CHA were classified according to the EUROCAT Subgroup of Congenital Anomalies version 2012 [18] and the International Classification of Diseases (ICD) coding system 9th revision. For cases registered from 2002 onwards, the ICD coding system 10th revision was used for classification. We included only major CHA cases, either as single heart anomalies, as part of complex heart anomalies (including cardiovascular anomalies) or as part of complex anomalies involving other organ systems. Diagnosis codes included were ICD9 745-746, 74707474 (excluding 74550 , persistent foramen ovale) and ICD10 Q20-Q26 (excluding Q2111, persistent foramen ovale), which include common arterial truncus, transposition of great vessels, single ventricle, ventricular/atrial/atrioventricular septal defects, tetralogy of Fallot, triscuspid atresia and stenosis, Ebstein's anomaly, pulmonary valve stenosis, pulmonary valve atresia, aortic valve atresia/stenosis, hypoplastic left/right heart syndrome, coarctation of aorta, total anomalous pulmonary venous return and patent ductus arteriosus. Cases born between 1 January 1997 and 31 December 2013 were eligible for this study. Exclusion criteria were: cases with genetic disorders, including chromosomal anomalies, microdeletions, monogenic disorders and those with known teratogenic causes; case mothers with a previous history of a malformed child or history unknown; and cases in which the mother never used any medication during pregnancy in order to reduce the selection bias of including mothers among the unexposed group who were generally 'healthy'. Cases were invited to participate in this study via the Pediatric Cardiology Clinic, University Medical Center Groningen (UMCG) and were asked to provide DNA samples. This study received a waiver from ethical clearance consideration by the Medical Ethical Committee of the UMCG.

\section{Drug exposure}

Exposed cases were defined as CHA cases whose mothers had used at least one of the following SRIs (ATC codes) at some point between 30 days before conception and 90 days of gestation: fluoxetine (N06AB03), citalopram (N06AB04), paroxetine (N06AB05), sertraline (N06AB06), fluvoxamine (N06AB08), escitalopram (N06AB10), venlafaxine (N06AX16) and duloxetine (N06AX21). The information on drug use in EUROCAT NNL was obtained primarily via pharmacy records, upon consent of the mother, and later verified by telephonic interviews to ensure the validity of the information obtained. The unexposed cases were CHA cases whose mothers had used any drugs other than SRIs during pregnancy. Variables like smoking during the pregnancy, alcohol intake during the pregnancy, maternal medical history and folic acid supplementation were obtained from a questionnaire given upon registration with EUROCAT NNL.

\section{Selection of candidate genes \& SNPs}

We selected ten genes that encode enzymes or proteins important in determining fetal exposure to SRIs: the CYP450 enzymes (CYP1A2, CYP2C9, CYP2C19 and CYP2D6), P-gp (ABCB1), SERT (SLC6A4) and serotonin receptors (HTR1A, HTR1B, HTR2A and HTR3B). The CYP450 metabolic enzymes are involved in the pharmacokinetics of SRIs and influence the drug concentration in the maternal circulation. Since all the SRIs examined in this study are substrates of P-gp, changes in P-gp expression or activity may alter the fetal exposure to SRIs [19,20]. SRIs inhibit the uptake of serotonin (5-HT) through SERT and 5-HT signals 
through serotonin receptors. Normal 5-HT signaling is important for normal development of fetal heart cells [21].

For the CYP1A2, CYP2C9, CYP2C19 and CYP2D6 genes, we selected 37 SNPs with known phenotypes of either 'ultrarapid metabolizer', 'rapid metabolizer', 'extensive metabolizer', 'intermediate metabolizer' or 'poor metabolizer' [22]. The selection of polymorphisms in ABCB1, SLC6A4 and serotonin receptor genes was based on their clinical effects on the SRI treatment. We selected eight SNPs in $A B C B 1$, two repeat markers in SLC6A4, two SNPs in HTR1A, two SNPs in HTR1B, five SNPs in HTR2A and two SNPs in HTR3B (Supplementary Table 1) [8,14,23-24]. SNPs with call rates of $<90 \%$ were excluded from the analysis.

\section{DNA collection}

An invitation letter and package was sent to the mother of each exposed case, followed by a reminder letter after 4 weeks, if necessary. Once written informed consent was received from the mothers (and children), we sent them the sample collection kit including cytobrushes to collect buccal cell samples (Isohelix SK-1 swab kits with Isohelix Dri-capsules, Cell Projects Ltd, UK). Clear instructions about how to use the sample collection kit were provided, together with a link to an instructional video (in Dutch). Mothers (and children) were asked to return the cytobrushes to the researchers in prepaid mail envelopes, with a silica gel enclosed. A reminder letter was sent if we did not receive the samples after 4 weeks. Each collection tube containing the samples was labeled with the identifier code and with 'Mother' or 'Child'. For the unexposed cases, DNA samples were retrieved from CHA patients from the Department of Genetics, UMCG who had consented to the use of their residual materials in future research. DNA was obtained from the blood and the isolation process was performed in the same facility as the samples from exposed cases.

\section{Genotyping}

DNA samples received from the exposed cases were labeled and stored until they were genotyped. DNA from exposed cases was extracted from the buccal cells using Isohelix DNA isolation kit (DDK-50/DDK-3, Cell Projects Ltd, UK). SNP genotyping for $C Y P_{s}$, $A B C B 1$ and $H T R$ genes was performed using $10 \mathrm{ng}$ of DNA samples using the iPLEX ${ }^{\circledast}$ Gold platform (Agena Bioscience GmbH, Hamburg, Germany) according to the standard protocol. The region of interest was amplified by PCR using gene-specific primers, followed by single base extension using the iPLEX Gold cocktail of primer, enzyme, buffer and terminator nucleotides, resulting in extended fragments with a specific mass for each allele. The mass was detected by the MassAR$\mathrm{RAY}^{\circledR}$ System and genotype calling was performed using the MassARRAY ${ }^{\circledR}$ Typer Analyzer 4.0 software tools (Agena Bioscience GmbH or Sequenom, Hamburg, Germany). Manual inspection and adjustment of the genotype classifications was also performed by authors on all the SNPs with call rates of less than $90 \%$. For the SLC6A4 repeat markers, the regions of 5-HTTLPR and 5-HTTVNTR were amplified by PCR using specific primers. Amplified DNA fragments were separated by electrophoresis: 5-HTTLPR long and short alleles (530 and 486 bp, respectively) and 5-HTTVNTR STin2.9, STin2.10 and STin2.12 (250, 271 and 302 bp, respectively). Details on primer sequences are available upon request.

\section{Phenotype \& genotype scoring}

The genotypes of CYP enzyme polymorphisms were grouped into phenotypes that depict the functionality of the enzymes (i.e., normal metabolizer, poor metabolizer or rapid metabolizer, etc.), and were reported according to the standardized terms from the Clinical Pharmacogenomics Implementation Consortium $[25,26]$. Since the CYP enzymes in the fetus are not fully developed during the first trimester, only the genotype from the mothers was analyzed.

The risk of CHA was determined for each genetic variation of the ABCB1, HTR1A, HTR1B, HTR2A and $H T R 2 B$ genes using a recessive model and for the SLC6A4 gene using a dominant model, based on the number of exposed cases to perform the analysis. To further explore the cumulative effect of $A B C B 1$ SNPs, we calculated a genetic score per individual based on the number of risk alleles present as done previously [27-29]. The score is associated with the transport of SRIs through P-gp. In the mother, P-gp is expressed in the intestines, liver and kidney where it helps to eliminate substrate drugs, while P-gp in the placenta limits drug transport into the fetal circulation. A maternal $A B C B 1$ genotype encoding for reduced P-gp function increases the plasma drug concentration available for transfer through the placenta, while the same genotype in the fetus increases the transfer of the drug into the fetus. Seven SNPs in the $A B C B 1$ gene previously associated with reduced expression or function were included in the scoring: rs1045642, rs1128503, rs1882478, rs2032582, rs2235040, rs4148739 and rs9282564. The risk alleles can occur in a homozygous or heterozygous form; therefore each individual could have zero, one or two alleles for each SNP, resulting in a cumulative risk score up to 14 . For the SLC6A4 5-HTTLPR and 5-HTTVNTR polymorphisms, the cumulative score was up to four. 


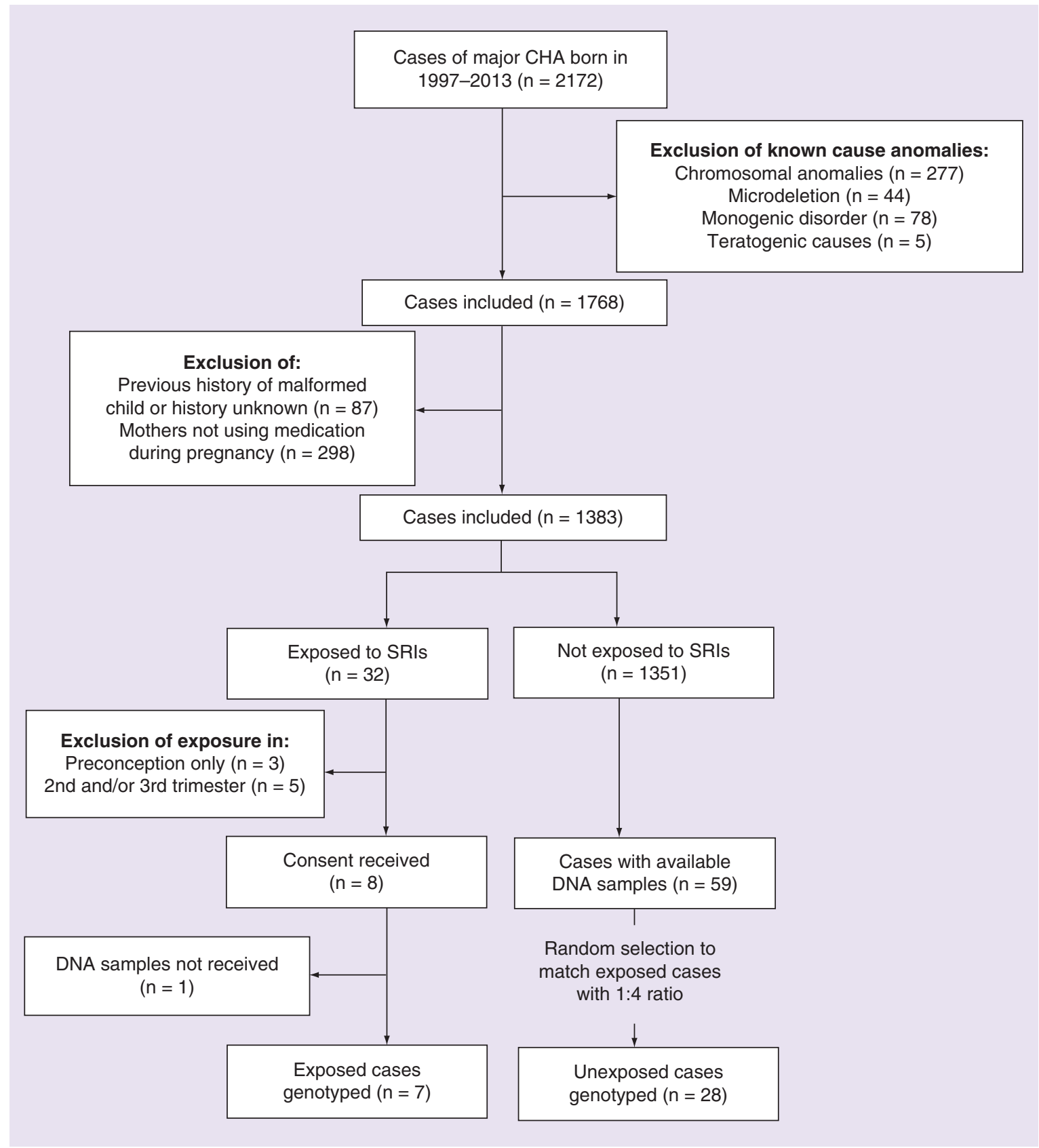

Figure 1. Case sampling.

\section{Statistical analysis}

Deviations from Hardy-Weinberg equilibrium were tested using Pearson's $\chi^{2}$ test. To test for the effect of pharmacogenetic predictors (genotype) and prenatal exposure to SRIs (environment) on the risk of fetal CHA, we determined the departure from multiplicative interaction between gene and environment using multivariable logistic regression and expressed as interaction odds ratio (OR) and 95\% CI. An OR of more than 1 indicates that the presence of both pharmacogenetic predictors and SRI use increases the risk of CHA.

\section{Results}

\section{Case sampling}

From 2172 CHA cases born between 1997 and 2013 and registered in EUROCAT NNL, we selected 1383 cases that matched the inclusion criteria (Figure 1). For the exposed cases, 24 case mothers were invited to participate in the study and 8 case-mother dyads gave their consent. For cases under the age of 12, written informed consent was obtained from their mothers. The DNA samples were available for five exposed dyads and two mothers-only (with deceased child) cases; four exposed case-mother dyads and two 
mothers-only cases provided their DNA samples, and the samples of one case-mother dyad were retrieved from the clinical diagnostic laboratory. The number of unexposed cases was chosen to be four-times the number of exposed cases because increasing the ratio would not have added to the significance of the results. Therefore, 28 unexposed case-mother dyads were randomly selected from the available DNA samples.

The characteristics of all the cases and mothers can be found in Table 1. Majority of our cases and case mothers are Caucasians (91.4\%). Of the seven exposed case-mothers, three were recorded to have depression. No chronic illness was registered of the other four mothers, but we can assume they will all have had depression or anxiety symptoms. Of the 28 unexposed case-mothers, none had a registered psychiatric illness. The SRIs used by the case-mothers were paroxetine (three), fluoxetine (two), venlafaxine (one), and paroxetine and venlafaxine (one). None of the exposed mothers were using psychoactive drugs other than SRIs and none of the unexposed mothers were using psychoactive drugs.

Other types of medications used by these mothers in the first trimester are: antiemetics (six), analgesics (six), hormone preparations (five), antacids (four), laxatives (four), antibiotics (three), antihistamines (two), thyroid preparation (one), cholesterol lowering agent (one) and cough preparation (one).

\section{Genotyping}

A total of 65 DNA samples were obtained and genotyped: 12 samples from the exposed cases (five children and seven mothers) and 53 samples from the unexposed cases (28 children and 25 mothers). Genotype and allele frequencies for all case-mother dyads are listed in Table 2. Out of 58 polymorphisms analyzed, five SNPs (CYP2D6 *4, *6, *8, ${ }^{*} 17$ and *41) failed to be genotyped. Out of 53 SNPs, four SNPs $\left(C Y P 2 D 6^{*} 2,{ }^{*}\right),{ }^{*} 11$ and $\left.{ }^{*} 12\right)$ had allele calling rates of less than $90 \%$ and the genotype frequency for HTR2A rs7997012 was not in Hardy-Weinberg equilibrium $(\mathrm{p}=0.03)$. Due to the different call rates among SNPs, the number of case-mother dyads differed for each $\mathrm{G} \times \mathrm{E}$ interaction analysis.

\section{CYP enzyme \& P-glycoprotein phenotypes}

The interaction between maternal CYP enzyme phenotypes and SRI exposure does not indicate an effect on the risk of CHA. Among cases exposed to paroxetine $(\mathrm{n}=4)$, all the case-mothers were normal CYP2D6 metabolizers (Supplementary Table 2). Two cases were exposed to venlafaxine and one of them was an intermediate CYP2C19 metabolizer. Fluoxetine was used by two case-mothers who were both normal
Table 1. Characteristics of case-mother dyads included in the study $(n=35)$.

\begin{tabular}{|c|c|c|}
\hline Characteristics & $\mathbf{n}$ & $\%$ \\
\hline \multicolumn{3}{|l|}{ Child's sex } \\
\hline Boy & 27 & 77.1 \\
\hline Girl & 8 & 22.9 \\
\hline \multicolumn{3}{|l|}{ Year of birth } \\
\hline $2003-2007$ & 24 & 68.6 \\
\hline 2008-2013 & 11 & 31.4 \\
\hline First pregnancy & 8 & 22.9 \\
\hline \multicolumn{3}{|l|}{ Types of birth } \\
\hline Live birth & 33 & 94.3 \\
\hline Termination of pregnancy & 2 & 5.7 \\
\hline \multicolumn{3}{|l|}{ Types of CHA } \\
\hline Single & 22 & 62.9 \\
\hline Complex & 13 & 37.1 \\
\hline \multicolumn{3}{|l|}{ Subtypes of $\mathrm{CHA}^{\dagger}$} \\
\hline $\begin{array}{l}\text { Cardiac cambers and connections, } \\
\text { ICD10 Q20 }\end{array}$ & 5 & 14.3 \\
\hline Cardiac septa, ICD10 Q21 & 11 & 31.4 \\
\hline $\begin{array}{l}\text { Pulmonary and tricuspid valves, } \\
\text { ICD10 Q22 }\end{array}$ & 2 & 5.7 \\
\hline Aortic and mitral valves, ICD10 Q23 & 22 & 62.9 \\
\hline Great arteries, ICD10 Q25 & 12 & 34.3 \\
\hline $\begin{array}{l}\text { Maternal age at delivery, mean } \\
\text { years (range) }\end{array}$ & 31 & $\begin{array}{l}24- \\
39\end{array}$ \\
\hline \multicolumn{3}{|l|}{ Maternal education level } \\
\hline Low & 2 & 5.7 \\
\hline Middle & 18 & 51.4 \\
\hline High & 15 & 42.9 \\
\hline Folic acid use during pregnancy & 33 & 94.3 \\
\hline Smoking during first trimester & 6 & 17.1 \\
\hline Alcohol intake in the first trimester & 14 & 40.0 \\
\hline \multicolumn{3}{|l|}{ Medication use in the first trimester } \\
\hline SRIs & 7 & 20 \\
\hline Other medication $^{\ddagger}$ & 23 & 65.7 \\
\hline \multicolumn{3}{|l|}{ Maternal medical history } \\
\hline Gestational diabetes & 3 & 8.6 \\
\hline Congenital anomalies & 4 & 11.4 \\
\hline Chronic disease & 6 & 17.1 \\
\hline \multicolumn{3}{|c|}{$\begin{array}{l}\text { 'More than one subtype is counted for cases of complex CHA. } \\
\text { *Other than SRIs (for exposed group) and folic acid/ } \\
\text { supplements (for unexposed group); within } 30 \text { days before } \\
\text { conception and } 90 \text { days in the first trimester. } \\
\text { CHA: Congenital heart anomaly; ICD-10: } 10 \text { th revision of the } \\
\text { Interntional Statistical Classification of Diseases and Related } \\
\text { Health Problems; SRI: Serotonin reuptake inhibitor. }\end{array}$} \\
\hline
\end{tabular}


Research Article Daud, Bergman, Kerstjens-Frederikse et al.

\begin{tabular}{|c|c|c|c|c|c|c|c|c|c|c|}
\hline $\begin{array}{l}\text { Gene/ } \\
\text { SNPs }\end{array}$ & rs number & $\begin{array}{l}\text { WT/VT } \\
\text { allele }\end{array}$ & wt/wt & $w t / v t$ & $v t / v t$ & NA & $\begin{array}{l}\text { Allele } \\
\text { calling rate }\end{array}$ & $\begin{array}{l}\text { Variant } \\
\text { allele fq }\end{array}$ & $\begin{array}{l}\text { Variant allele } \\
\text { fq (European) }\end{array}$ & $\begin{array}{l}\text { HWE } \\
\text { p-value }\end{array}$ \\
\hline \multicolumn{11}{|c|}{ CYP1A2 } \\
\hline & rs2069521 & $\mathrm{G} / \mathrm{A}$ & 62 & 1 & 0 & 2 & 96.9 & 0.01 & 0.02 & 0.95 \\
\hline & rs2069526 & T/G & 62 & 1 & 0 & 2 & 96.9 & 0.01 & 0.02 & 0.95 \\
\hline & rs4646425 & $\mathrm{C} / \mathrm{T}$ & 62 & 1 & 0 & 2 & 96.9 & 0.01 & 0.02 & 0.95 \\
\hline & rs4646427 & $\mathrm{T} / \mathrm{C}$ & 63 & 1 & 0 & 1 & 98.5 & 0.01 & 0.02 & 0.95 \\
\hline & rs2472304 & G/A & 4 & 27 & 32 & 2 & 96.9 & 0.72 & 0.6 & 0.59 \\
\hline & rs2470890 & $\mathrm{C} / \mathrm{T}$ & 5 & 26 & 33 & 1 & 98.5 & 0.72 & 0.6 & 0.97 \\
\hline \multicolumn{11}{|c|}{ CYP2C9 } \\
\hline *2 & rs1799853 & $\mathrm{C} / \mathrm{T}$ & 65 & 0 & 0 & 0 & 100 & 0 & 0.12 & NA \\
\hline *3 & rs1057910 & $\mathrm{A} / \mathrm{C}$ & 57 & 7 & 0 & 1 & 98.5 & 0.05 & 0.07 & 0.64 \\
\hline *4 & rs56165452 & T/A & 62 & 1 & 0 & 2 & 96.9 & 0.01 & $0^{+}$ & 0.95 \\
\hline *6 & rs9332131 & A/DEL & 62 & 0 & 0 & 3 & 95.4 & 0 & 0 & NA \\
\hline$* 5$ & rs 28371686 & $\mathrm{C} / \mathrm{G}$ & 65 & 0 & 0 & 0 & 100 & 0 & 0 & NA \\
\hline *8 & rs7900194 & $\mathrm{G} / \mathrm{A}$ & 64 & 0 & 0 & 1 & 98.5 & 0 & 0 & NA \\
\hline *11 & rs 28371685 & $\mathrm{C} / \mathrm{T}$ & 65 & 0 & 0 & 0 & 100 & 0 & 0 & NA \\
\hline$* 13$ & rs72558187 & $\mathrm{T} / \mathrm{C}$ & 65 & 0 & 0 & 0 & 100 & 0 & 0 & NA \\
\hline$* 15$ & rs72558190 & C/A & 65 & 0 & 0 & 0 & 100 & 0 & $0^{+}$ & NA \\
\hline \multicolumn{11}{|c|}{ CYP2C19 } \\
\hline *2 & rs 4244285 & G/A & 51 & 12 & 2 & 0 & 100 & 0.12 & 0.15 & 0.24 \\
\hline$* 3$ & rs4986893 & $\mathrm{G} / \mathrm{A}$ & 65 & 0 & 0 & 0 & 100 & 0 & 0 & NA \\
\hline *4 & rs28399504 & $A / G$ & 59 & 1 & 0 & 5 & 92.3 & 0.01 & 0 & 0.95 \\
\hline *5 & rs56337013 & $\mathrm{C} / \mathrm{T}$ & 65 & 0 & 0 & 0 & 100 & 0 & $0^{\ddagger}$ & NA \\
\hline *6 & rs 72552267 & $\mathrm{G} / \mathrm{A}$ & 65 & 0 & 0 & 0 & 100 & 0 & 0 & NA \\
\hline$* 7$ & rs72558186 & T/A & 64 & 0 & 0 & 1 & 98.5 & 0 & $0^{\ddagger}$ & NA \\
\hline$\star 8$ & rs41291556 & $\mathrm{T} / \mathrm{C}$ & 64 & 0 & 0 & 1 & 98.5 & 0 & 0 & NA \\
\hline$\star 9$ & rs17884712 & $\mathrm{G} / \mathrm{C}$ & 65 & 0 & 0 & 0 & 100 & 0 & 0 & NA \\
\hline$* 10$ & rs6413438 & $\mathrm{C} / \mathrm{T}$ & 65 & 0 & 0 & 0 & 100 & 0 & 0 & NA \\
\hline *17 & rs 12248560 & $\mathrm{C} / \mathrm{T}$ & 35 & 23 & 3 & 4 & 93.8 & 0.24 & 0.22 & 0.75 \\
\hline \multicolumn{11}{|c|}{ CYP2D6 } \\
\hline *2 & rs16947 & $\mathrm{G} / \mathrm{A}$ & 27 & 18 & 9 & 11 & 83.1 & 0.33 & 0.34 & 0.06 \\
\hline$* 3 A$ & rs35742686 & A/DEL & 61 & 0 & 0 & 4 & 93.8 & 0 & 0.02 & NA \\
\hline$* 7$ & rs5030867 & $\mathrm{A} / \mathrm{C}$ & 64 & 0 & 0 & 1 & 98.5 & 0 & 0 & NA \\
\hline *9 & rs5030656 & AAG/DEL & 13 & 0 & 0 & 52 & 20 & 0 & 0.03 & NA \\
\hline *10 & rs1065852 & $\mathrm{C} / \mathrm{T}$ & 39 & 22 & 4 & 0 & 100 & 0.23 & 0.2 & 0.71 \\
\hline *11 & rs5030863 & $\mathrm{G} / \mathrm{C}$ & 44 & 0 & 0 & 21 & 67.7 & 0 & NA & NA \\
\hline *12 & rs5030862 & $\mathrm{G} / \mathrm{A}$ & 56 & 0 & 0 & 9 & 86.2 & 0 & 0 & NA \\
\hline \multicolumn{11}{|l|}{$A B C B 1$} \\
\hline & rs1128503 & $\mathrm{C} / \mathrm{T}$ & 19 & 29 & 14 & 3 & 95.4 & 0.46 & 0.42 & 0.65 \\
\hline
\end{tabular}


Table 2. Genotype frequency of study SNPs in case-mother dyad samples ( $n=65)$ (cont.).

\begin{tabular}{|c|c|c|c|c|c|c|c|c|c|c|}
\hline $\begin{array}{l}\text { Gene/ } \\
\text { SNPs }\end{array}$ & rs number & $\begin{array}{l}\text { WT/VT } \\
\text { allele }\end{array}$ & wt/wt & wt/vt & $v t / v t$ & NA & $\begin{array}{l}\text { Allele } \\
\text { calling rate }\end{array}$ & $\begin{array}{l}\text { Variant } \\
\text { allele fq }\end{array}$ & $\begin{array}{l}\text { Variant allele } \\
\text { fq (European) }{ }^{\dagger}\end{array}$ & $\begin{array}{l}\text { HWE } \\
\text { p-value }\end{array}$ \\
\hline \multicolumn{11}{|c|}{$A B C B 1$ (cont.) } \\
\hline & rs1045642 & $\mathrm{C} / \mathrm{T}$ & 13 & 27 & 23 & 2 & 96.9 & 0.58 & 0.52 & 0.34 \\
\hline & rs1882478 & G/A & 40 & 20 & 2 & 3 & 95.4 & 0.19 & 0.26 & 0.79 \\
\hline & rs9282564 & $A / G$ & 46 & 14 & 2 & 3 & 95.4 & 0.15 & 0.08 & 0.48 \\
\hline & rs10256836 & $\mathrm{G} / \mathrm{C}$ & 3 & 26 & 34 & 2 & 96.9 & 0.75 & 0.3 & 0.48 \\
\hline \multicolumn{11}{|l|}{ SLC6A4 } \\
\hline \multicolumn{11}{|l|}{ HTR1A } \\
\hline & rs1364043 & $\mathrm{A} / \mathrm{C}$ & 38 & 21 & 4 & 2 & 96.9 & 0.23 & 0.21 & 0.64 \\
\hline & rs6295 & $\mathrm{G} / \mathrm{C}$ & 16 & 34 & 14 & 1 & 98.5 & 0.48 & 0.54 & 0.61 \\
\hline \multicolumn{11}{|l|}{ HTR1B } \\
\hline & rs6296 & $\mathrm{G} / \mathrm{C}$ & 30 & 24 & 9 & 2 & 96.9 & 0.33 & 0.74 & 0.26 \\
\hline & rs6298 & $C / T$ & 30 & 24 & 9 & 2 & 96.9 & 0.33 & 0.26 & 0.26 \\
\hline \multicolumn{11}{|l|}{ HTR2A } \\
\hline & rs7997012 & $\mathrm{C} / \mathrm{T}$ & 25 & 23 & 16 & 1 & 98.5 & 0.43 & 0.43 & 0.03 \\
\hline & rs1176744 & $\mathrm{A} / \mathrm{C}$ & 37 & 23 & 3 & 2 & 96.9 & 0.23 & 0.31 & 0.81 \\
\hline & rs3831455 & TCC/DEL & 63 & 0 & 0 & 2 & 96.9 & 0 & NA & NA \\
\hline
\end{tabular}

CYP2C9 and CYP2D6 metabolizers. Therefore, we cannot determine the effect of metabolic enzyme phenotypes on the risk of CHA associated with the use of SRIs among our case-mothers.

For $A B C B 1$, there was no change in the risk of CHA with any of the $A B C B 1$ SNPs in the mothers and the children, except for maternal rs 1128503 (not significant, Table 3). Due to the low number of sample, the risks were not corrected for maternal risk factors, such as maternal obesity, history of alcohol and illicit drug use. For the maternal genotype, the mean score among the exposed case-mothers was $3.9 \pm 0.7$, while the mean scores of the unexposed case mothers was $4.3 \pm 1.9(p=0.41)$. The distribution of the genetic scores of the exposed and unexposed cases is shown in Figure 2. The mean genetic score of the exposed cases (children) was $5.0 \pm 1.9$ and $4.4 \pm 1.8$ for the unexposed cases $(p=0.47)$.

\section{Serotonin transporter \& receptor}

polymorphisms

The LL genotype of the SLC6A4 5-HTTLPR and 12/12 genotype of 5-HTTVNTR indicated an increase in the risk of CHA among the cases exposed to SRIs, but our sample size was too small to reach statistical 
significance (Table 3). The mean genetic scores of the exposed mothers tended to be higher than those of the unexposed mothers $(2.5 \pm 0.8$ vs $1.88 \pm 0.7$, respectively; $\mathrm{p}=0.061$ ) (Figure 3). Meanwhile, the mean genetic scores of the exposed and unexposed cases (children) were comparable $(2.4 \pm 0.5$ and $2.18 \pm 0.8$, respectively; $\mathrm{p}=0.57)$.

For fetal 5-HT receptors, the SNPs in HTR1A, $H T R 1 B$ and $H T R 3 B$ showed increase in the interaction $\mathrm{OR}$, although none achieved statistical significance (Table 3). We then calculated the genetic scores for these SNPs, which included HTR1A rs1364043, HTR1B rs6296, HTR1B rs6298 and HTR3B rs1176744 (maximum score of 8). The mean genetic score for exposed cases tended to be higher compared with unexposed cases $(3.4 \pm 2.2$ vs $1.9 \pm 1.6$, respectively; $\mathrm{p}=0.065$ ), and the distribution was skewed toward higher genetic scores (Figure 4).

Table 3. Interaction odds ratio of the multiplicative interaction between each serotonin reuptake inhibitors of the $A B C B 1$ gene (coding for P-glycoprotein) and HTR genes (coding for the serotonin receptors) and serotonin reuptake inhibitors exposure on the risk of congenital heart anomalies.

\begin{tabular}{|c|c|c|c|c|c|c|}
\hline \multirow[t]{2}{*}{ Gene/SNPs } & \multicolumn{3}{|c|}{ Case mothers with variant alleles, $\mathrm{n}(\%)$} & \multicolumn{3}{|c|}{ Cases with variant alleles, $\mathrm{n}(\%)$} \\
\hline & $\begin{array}{l}\text { Exposed, } \\
n(\%) n=7\end{array}$ & $\begin{array}{l}\text { Unexposed } n \\
(\%) n=25\end{array}$ & OR (95\% Cl) & $\begin{array}{l}\text { Exposed } \\
n(\%) n=5\end{array}$ & $\begin{array}{l}\text { Unexposed } \\
n(\%) n=28\end{array}$ & OR (95\% Cl) \\
\hline \multicolumn{7}{|l|}{$A B C B 1$} \\
\hline rs1045642 & $7(100.0)$ & $19(76.0)$ & $0.94(0.48-41.82)$ & $3(60.0)$ & $21(75.0)$ & $0.43(0.058-053.14)$ \\
\hline rs1128503 & $6(85.7)$ & $14(56.0)$ & $3.86(0.4-37.58)$ & $3(60.0)$ & $20(71.4)$ & $0.53(0.072-073.82)$ \\
\hline rs1882478 & $2(28.6)$ & $9(36.0)$ & $0.64(0.13-13.06)$ & $2(40.0)$ & $9(32.1)$ & $0.80(0.32-31.99)$ \\
\hline rs2032582 & $6(58.7)$ & $15(60.0)$ & $0.95(0.52-51.76)$ & $3(60.0)$ & $20(71.4)$ & $0.52(0.086-083.59)$ \\
\hline rs2235040 & $2(28.6)$ & $8(32.0)$ & $0.71(0.19-12.67)$ & $2(40.0)$ & $8(28.6)$ & $0.89(0.38-32.10)$ \\
\hline rs4148739 & $2(28.6)$ & $7(28.0)$ & $0.71(0.24-22.09)$ & $2(40.0)$ & $8(28.6)$ & $0.89(0.38-32.10)$ \\
\hline rs9282564 & 0 & $7(28.0)$ & - & $1(20.0)$ & $8(28.6)$ & $0.58(0.07-05.08)$ \\
\hline rs10256836 & $7(100)$ & $22(88.0)$ & $0.84(0.32-32.18)$ & $5(100)$ & $26(92.9)$ & - \\
\hline \multicolumn{7}{|l|}{ SLC6A4 } \\
\hline & $\mathrm{n}=6$ & $\mathrm{n}=24$ & & $\mathrm{n}=5$ & $\mathrm{n}=28$ & \\
\hline \multirow[t]{2}{*}{ 5-HTTLPR (LL) } & $2(33.3)$ & $5(20.8)$ & $1.90(0.27-13.52)$ & $1(20)$ & $5(17.9)$ & $1.15(0.11-12.62)$ \\
\hline & $\mathrm{n}=6$ & $\mathrm{n}=25$ & & $\mathrm{n}=5$ & $\mathrm{n}=28$ & \\
\hline 5HTTVNTR (12/12) & $3(50)$ & $9(36)$ & $1.78(0.3-10.72)$ & $2(40)$ & $11(39.3)$ & $1.03(0.15-17.19)$ \\
\hline \multicolumn{7}{|l|}{ HTR1A } \\
\hline rs1364043 & & & & $3(60.0)$ & $9(32.1)$ & $3.0(0.42-21.30)$ \\
\hline rs6295 & & & & $5(100)$ & $21(75.0)$ & - \\
\hline \multicolumn{7}{|l|}{ HTR1B } \\
\hline rs6296 & & & & $3(60.0)$ & $11(39.3)$ & $2.18(0.31-15.29)$ \\
\hline rs6298 & & & & $3(60.0)$ & $11(39.3)$ & $2.18(0.31-15.29)$ \\
\hline \multicolumn{7}{|l|}{ HTR2A } \\
\hline rs6313 & & & & $2(40.0)$ & $13(46.4)$ & $0.72(0.10-15.01)$ \\
\hline rs6314 & & & & $1(20.0)$ & $6(21.4)$ & $0.88(0.082-089.38)$ \\
\hline rs1928040 & & & & $3(60.0)$ & $20(74.1)$ & $0.45(0.06-03.35)$ \\
\hline rs6311 & & & & $2(40.0)$ & $14(50.0)$ & $0.67(0.10-14.62)$ \\
\hline \multicolumn{7}{|l|}{ HTR3B } \\
\hline rs1176744 & & & & $4(80.0)$ & $11(39.3)$ & $5.82(0.57-59.32)$ \\
\hline rs3831455 & & & & 0 & $1(3.6)$ & - \\
\hline
\end{tabular}



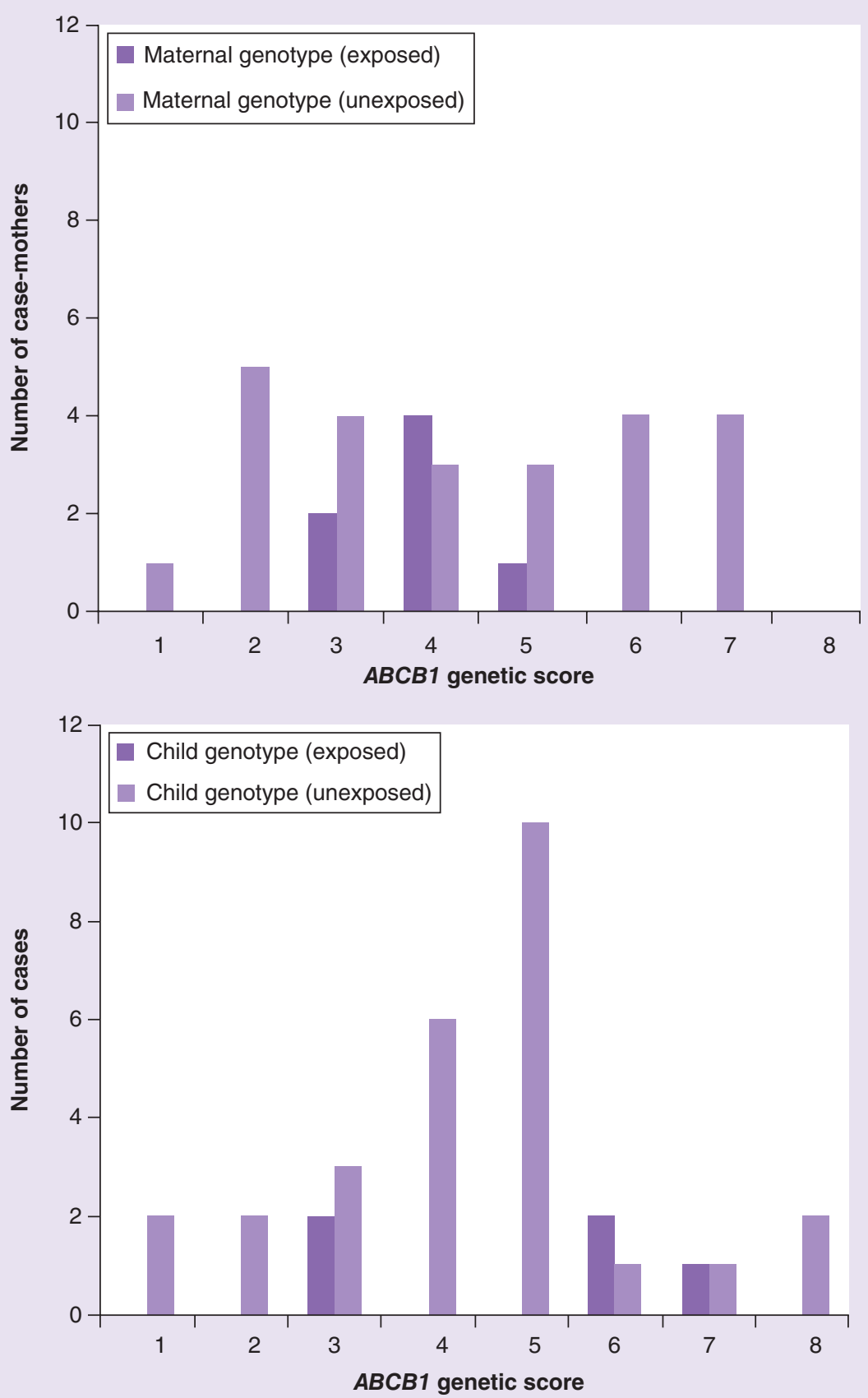

Figure 2. Distribution of maternal and child $A B C B 1$ genetic scoring associated with reduced P-glycoprotein function.

\section{Discussion}

In this exploratory study, we aimed to find associations between polymorphisms in ten genes involved in the metabolism of drugs in pregnant women and the occurrence of $\mathrm{CHA}$ in their children. Concerning the $A B C B 1$ SNPs, only maternal rs 1128503 had an increased, although nonsignificant, interaction OR and could therefore be associated with an increased risk of CHA following exposure to SRIs.
This SNP, together with rs1045642 (C3435T) and rs2030582 (G2677T/A), was previously associated with reduced expression/function of placental P-gp and shown to modulate the placental transfer of substrate drugs [32-35]. This modulation may affect the protective barrier against xenobiotics in the early stage of pregnancy. It has also been suggested that these SNPs play a role in the clinical response of SRIs because P-gp regulates the transport of 
SSRIs through the blood-brain barrier [36-41]. With regard to congenital anomalies, two previous observational studies reported that maternal and fetal C3435T increased fetal susceptibility to CHA and cleft lip following general medication use during pregnancy [42-44]. This association was not found in our study, probably because of the different types of medication included in the exposure groups, as we have focused on SRI use instead of medication use in general.

The $\mathrm{L}$ allele of the 5-HTTLPR and 12 repeats of the 5-HTTVNTR of SLC6A4 had previously been associated with higher efficacy or side effects of SRI treatment, effects proposed to be caused by a higher expression of SERT [45-49]. In this study, the G $\times \mathrm{E}$ interaction between these variants and SRI use tended
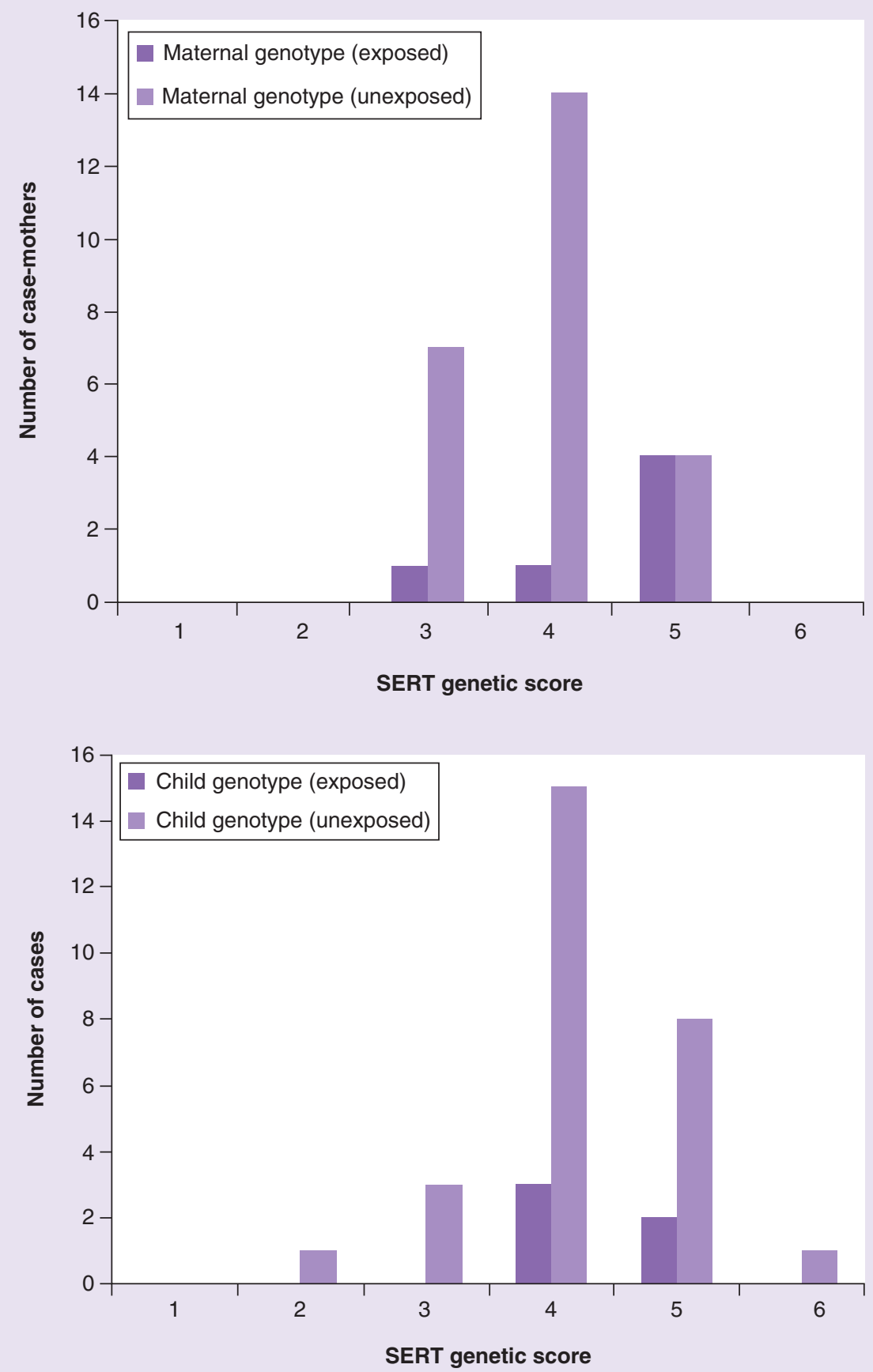

Figure 3. Distribution of maternal and child SLC6A4 genetic scoring associated with increased serotonin transporter function. 


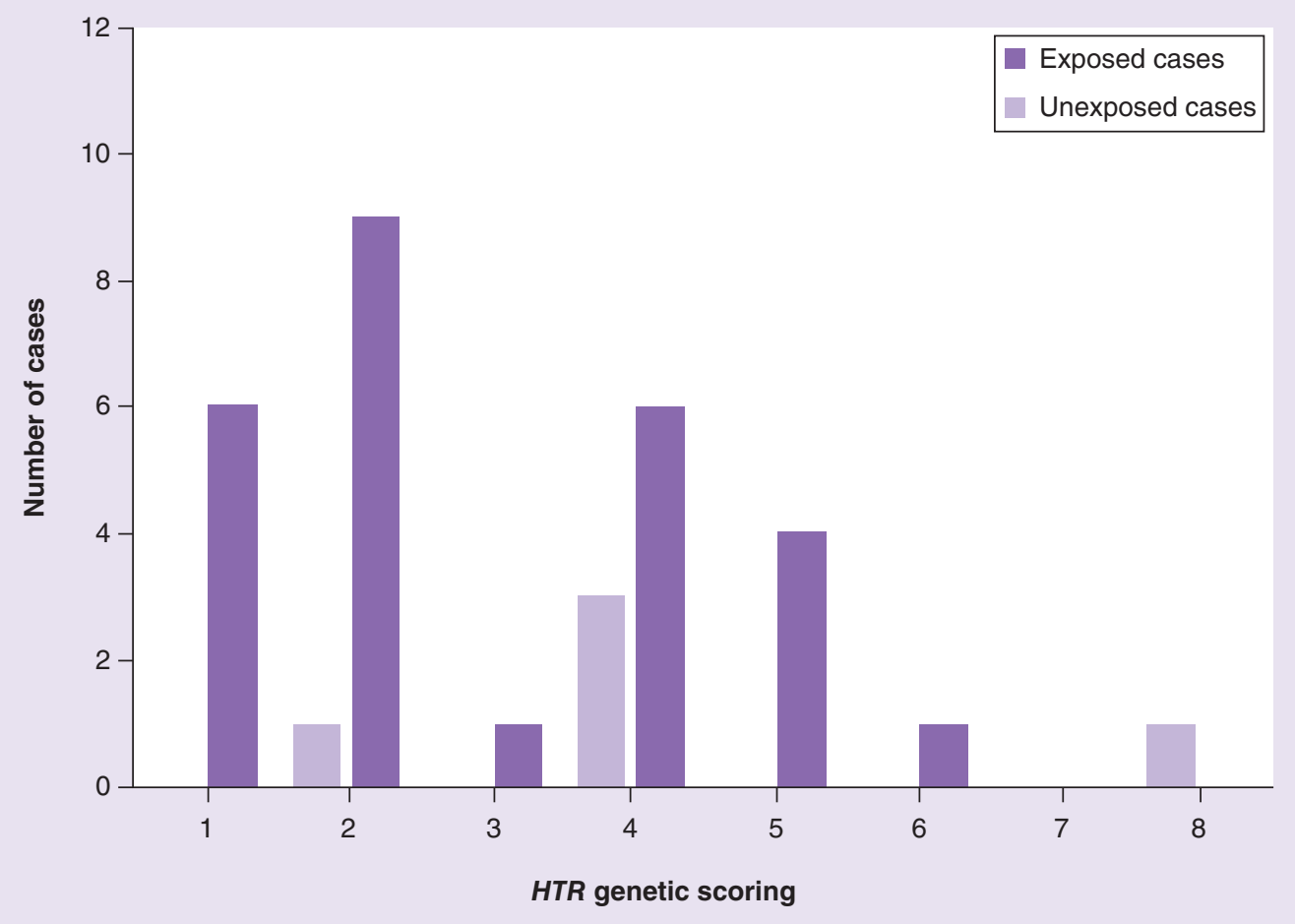

Figure 4. Distribution of child genetic scoring of HTR genes associated with increased interaction odds ratio.

to cause an increase in the risk of $\mathrm{CHA}$, but only for the maternal genotype interaction. Looking at the effect on the fetus, one would expect that the fetal SLC6A4 variant would have a larger effect on SERT expression in the placenta that is of fetal origin. However, SERT mRNA was also detected in epithelial cells of early decidua, which is the uterine lining of the maternal endometrium [50]. The increase in SERT expression may cause a higher response to SRIs, and is manifested by the increased inhibition of 5-HT uptake into the placenta. The exact mechanism seems to be intricate and unclear; however, we can hypothesize that the combination of SERT polymorphisms and SRI exposure might cause a disruption in the normal 5-HT level available for the transport into the fetal circulation.

Our study found four SNPs in HTR genes encoding for 5-HT receptors that showed a possibly increased risk of CHA after the exposure to SRIs, although the effect was not significant. Two of the SNPs, HTR1A rs1364043 and HTR1B rs6296, had previously been associated with an increased response to citalopram [24], while HTR3B rs1176744 had been shown to reduce the side effects of paroxetine [51]. However, these associations have not yet been replicated in larger studies. On the other hand, HTRIB rs6298 was associated with a reduced response to citalopram [24]. The role of genetic variations in
5-HT receptors needs further investigation given the importance of 5-HT signaling during embryogenesis, particularly in cell division, differentiation, migration and synaptogenesis [52]. Any alteration in the 5-HT level and receptor activity during this period could lead to susceptibility to faulty fetal heart development.

\section{Strengths \& limitations}

One of the strengths of this study is that it is the first attempt at elucidating the role of pharmacogenetics in the development of CHA associated with prenatal use of SRIs. A further strength is the $\mathrm{G} \times \mathrm{E}$ interaction approach, which is a powerful design for determining the contribution of genetics to adverse drug events or teratogenicity. Previous studies have identified several genetic variations associated with $\mathrm{CHA}$ in the presence of environmental factors like maternal obesity, tobacco use and folic acid intake [53-56]. A third strength is that the EUROCAT NNL database used in this study records complete information on maternal risk factors (i.e., smoking, alcohol and medication use). Since all cases were selected from the same database, any misclassification of exposure would be nondifferential among exposed and unexposed cases. Finally, we also included cases of terminated pregnancies, which are usually missing from the health surveillance databases. 
There are several limitations to this study. First, a case-only study can only measure the risk of the $\mathrm{G} \times \mathrm{E}$ interaction, not the separated risks of $\mathrm{G}$ or $\mathrm{E}$. Second, this design is vulnerable to population stratification, although we can assume this effect is minor in this study since the majority of our population is Caucasian [57]. Third, we cannot differentiate between different SRIs and doses in the analysis because of the limited number of cases exposed to SRIs and the exploratory nature of the study. The type of SRI might also be a relevant factor, since SRIs can have different pharmacokinetic and pharmacodynamic characteristics. Fourth, our participation rate was low (30\% among cases exposed to SRIs), despite a concerted effort to reduce barriers to participation that included sending reminders to potential participants and use of a noninvasive method of DNA collection. It is possible that the low participation was because mothers were reluctant to know whether the medication they took had contributed to the development of a heart defect in their child. They may also not have understood the benefit of pharmacogenetic tests or the results of this study for themselves.

In conclusion, maternal use of SRIs during the first trimester of pregnancy has long been studied for its association with fetal CHA, although the results to date have been conflicting. In this exploratory study, we were not able to find significant genetic variations that may modulate the risk of CHA in fetuses exposed to SRIs in the first trimester of pregnancy. Nevertheless, we found that polymorphisms of 5-HT receptors may play a role. Future studies will need a larger number of exposed cases and possibly to incorporate the effect of maternal $\mathrm{G} \times \mathrm{E}$ and fetal $\mathrm{G} \times \mathrm{E}$ contribution to CHA.

\section{Future perspective}

The use of pharmacogenetics as a tool in personalized drug therapy has been studied before, but the importance of this concept among pregnant patients is now taking the spotlight [58-61]. The pharmacogenetic parameters explored in this study are a part of a complex interplay between other genetic variants and environmental factors contributing to CHA. Potential gene-gene $(G \times G)$ or $G \times E$ interaction can occur within the maternal or fetal genotypes and also between maternal and fetal genotypes [62]. Based on our current, still limited knowledge about the pharmacogenetics of SRIs, we need more genetic studies among pregnant patients with depression in order to identify the safest treatment option for both the mothers and their unborn children.

\section{Acknowledgements}

We would like to thank B Sanjabi and B van Rijkom from the UMCG and R van Schaik from the Erasmus Medical Center Rotterdam for their help with the genotyping. We also thank $\mathrm{H}$ de Walle from EUROCAT NNL for her support throughout the study period and Ke Mc Intyre for help in editing this manuscript.

Financial \& competing interests disclosure

ANA Daud, JEH Bergman, WS Kerstjens-Frederikse, P van der Vlies, E Hak, RMF Berger, H Groen and B Wilffert declare that they have no conflicts of interest. EUROCAT NNL was funded by the Ministry of Health, Welfare and Sports,

\section{Summary points}

Role of genetic variations in the risk of drug-induced teratogenicity

- There are discrepancies in the reported risk of CHA associated with prenatal exposure to SRIs.

- Genetic polymorphisms that cause clinical changes in SRI response and side effects, might affect the fetus's exposure to these drugs.

- Genetic differences among fetuses exposed to SRIs may potentially explain their risk of having $\mathrm{CHA}$.

CYP enzyme \& P-glycoprotein ( $A B C B 1)$ phenotypes

- The effect of CYP enzyme phenotypes on the risk of CHA could not be determined due to limited sample sizes.

- Only the maternal rs1128503 of the $A B C B 1$ gene was found to cause an increase in the risk of $\mathrm{CHA}$, but the association was not significant.

Serotonin transporter (SLC6A4) \& serotonin receptor polymorphisms

- The maternal LL genotype of the SLC6A4 5-HTTLPR and 12/12 genotype of the 5-HTTVNTR showed an increase in the risk of CHA among exposed cases (not significant).

- For fetal serotonin receptors, several SNPs in HTR1A, HTR1B and HTR3B showed an increase in the risk of CHA among exposed cases (not significant).

\section{Conclusion}

- A gene-environment interaction study can be used to explore the role of pharmacogenetics in drug teratogenicity.

- Genetic risk scoring can be helpful for summarizing the cumulative risk of different pharmacogenetic risk alleles. 
The Netherlands. Genotyping analysis was paid for by the Ministry of Education in Malaysia. The funding sponsors had no role in the design of the study, data collection and analyses, interpretation of data or preparation of this manuscript. We are also really grateful to all the participants in this study. The authors have no other relevant affiliations or financial involvement with any organization or entity with a financial interest in or financial conflict with the subject matter or materials discussed in the manuscript apart from those disclosed.

No writing assistance was utilized in the production of this manuscript.

\section{References}

Papers of special note have been highlighted as: • of interest;

• of considerable interest

1 Charlton RA, Jordan S, Pierini A et al. Selective serotonin reuptake inhibitor prescribing before, during and after pregnancy: a population-based study in six European regions. BJOG 122(7), 1010-1020 (2015).

2 Andrade SE, Raebel MA, Brown J et al. Use of antidepressant medications during pregnancy: a multisite study. Am. J. Obstet. Gynecol. 198(2), 194-195 (2008).

3 Alwan S, Reefhuis J, Rasmussen SA, Friedman JM, National Birth Defects Prevention Study. Patterns of antidepressant medication use among pregnant women in a United States population. J. Clin. Pharmacol. 51(2), 264-270 (2011).

4 Wurst KE, Poole C, Ephross SA, Olshan AF. First trimester paroxetine use and the prevalence of congenital, specifically cardiac, defects: a meta-analysis of epidemiological studies. Birth defects Res. A Clin. Mol. Teratol. 88(3), 159-170 (2010).

5 Grigoriadis S, VonderPorten EH, Mamisashvili L et al. Antidepressant exposure during pregnancy and congenital malformations: is there an association? A systematic review and meta-analysis of the best evidence. J. Clin. Psychiatry. 74(4), e293-e308 (2013).

6 Myles N, Newall H, Ward H, Large M. Systematic metaanalysis of individual selective serotonin reuptake inhibitor medications and congenital malformations. Aust. N. Z. J. Psychiatry 47(11), 1002-1012 (2013).

7 Wang S, Yang L, Wang L, Gao L, Xu B, Xiong Y. Selective serotonin reuptake inhibitors (SSRIs) and the risk of congenital heart defects: a meta-analysis of prospective cohort studies. J. Am. Heart Assoc. 4(5), e001681 (2015).

8 Daud A, Bergman J, Kerstjens-Frederikse W, Groen H, Wilffert B. The risk of congenital heart anomalies following prenatal exposure to serotonin reuptake inhibitors - is pharmacogenetics the key? Int. J. Mol. Sci. 17(8), E1333 (2016).

9 Swen JJ, Wilting I, de Goede AL et al. Pharmacogenetics: from bench to byte. Clin. Pharmacol. Ther. 83(5), 781-787 (2008).

10 Swen JJ, Nijenhuis M, de Boer A et al. Pharmacogenetics: from bench to byte-an update of guidelines. Clin. Pharmacol. Ther. 89(5), 662-673 (2011).

\section{Ethical conduct of research}

All procedures performed in studies involving human participants were in accordance with the ethical standards of the institutional and/or national research committee and with the 1964 Helsinki declaration and its later amendments or comparable ethical standards. Informed consent was obtained from all the individual participants included in the study.

\section{Supplementary data}

To view the supplementary data that accompany this paper please visit the journal website at: www.futuremedicine.com/ doi/full/10.2217/pgs-2017-0036

11 Daud AN, Bergman JE, Bakker MK et al. Pharmacogenetics of drug-induced birth defects: the role of polymorphisms of placental transporter proteins. Pharmacogenomics 15(7), 1029-1041 (2014).

12 Fabbri C, Minarini A, Niitsu T, Serretti A. Understanding the pharmacogenetics of selective serotonin reuptake inhibitors. Expert Opin. Drug Metab. Toxicol. 10(8), 1093-1118 (2014).

13 Kroeze Y, Zhou H, Homberg JR. The genetics of selective serotonin reuptake inhibitors. Pharmacol. Ther. 136(3), 375-400 (2012).

14 Wilkie MJ, Smith G, Day RK et al. Polymorphisms in the SLC6A4 and HTR2A genes influence treatment outcome following antidepressant therapy. Pharmacogenomics J. 9(1), 61-70 (2009).

15 Hassanzadeh J, Moradzadeh R, Rajaee Fard A, Tahmasebi S, Golmohammadi P. A comparison of case-control and caseonly designs to investigate gene-environment interactions using breast cancer data. Iran. J. Med. Sci. 37(2), 112-118 (2012).

16 Li D, Conti DV. Detecting gene-environment interactions using a combined case-only and case-control approach. Am. J. Epidemiol. 169(4), 497-504 (2009).

17 Albert PS, Ratnasinghe D, Tangrea J, Wacholder S. Limitations of the case-only design for identifying geneenvironment interactions. Am. J. Epidemiol. 154(8), 687-693 (2001).

18 European Surveillance of Congenital Anomalies (EUROCAT). Subgroups of congenital anomalies (Version 2012).

www.eurocat-network.eu/content/

19 Akamine Y, Yasui-Furukori N, Ieiri I, Uno T. Psychotropic drug-drug interactions involving P-glycoprotein. CNS Drugs 26(11), 959-973 (2012).

20 Hodges LM, Markova SM, Chinn LW et al. Very important pharmacogene summary: $A B C B 1$ (MDR1, P-glycoprotein). Pharmacogenet. Genomics 21(3), 152-161 (2011).

21 Sadler TW. Selective serotonin reuptake inhibitors (SSRIs) and heart defects: potential mechanisms for the observed associations. Reprod. Toxicol. 32(4), 484-489 (2011).

22 The Human Cytochrome P450 (CYP) Allele Nomenclature Database. Allele nomenclature for 
Cytochrome P450 enzymes. www.cypalleles.ki.se/

23 Gex-Fabry M, Eap CB, Oneda B et al. CYP2D 6 and $A B C B 1$ genetic variability: influence on paroxetine plasma level and therapeutic response. Ther. Drug Monit. 30(4), 474-482 (2008).

24 Villafuerte SM, Vallabhaneni K, Sliwerska E, McMahon FJ, Young EA, Burmeister M. SSRI response in depression may be influenced by SNPs in HTR1B and HTR1A. Psychiatr. Genet. 19(6), 281-291 (2009).

25 Cariaso M, Lennon G. SNPedia: a wiki supporting personal genome annotation, interpretationand analysis. Nucleic Acids Res. 40, D1308-D1312 (2012).

26 Caudle KE, Dunnenberger HM, Freimuth RR et al. Standardizing terms for clinical pharmacogenetic test results: consensus terms from the Clinical Pharmacogenetics Implementation Consortium (CPIC). Genet. Med.19, 215-223 (2016).

27 Swen JJ, Guchelaar H-JJ, Baak-Pablo RF, Assendelft WJJ, Wessels JAM. Genetic risk factors for Type 2 diabetes mellitus and response to sulfonylurea treatment. Pharmacogenet. Genomics 21(8), 461-468 (2011).

28 Nelveg-Kristensen KE, Madsen MB, Torp-Pedersen C et al. Pharmacogenetic risk stratification in angiotensin-converting enzyme inhibitor-treated patients with congestive heart failure: a retrospective cohort study. PLoS ONE. 10(12), e0144195 (2015).

29 Meigs JB, Shrader P, Sullivan LM et al. Genotype score in addition to common risk factors for prediction of Type 2 diabetes. N. Engl. J. Med. 359(21), 2208-2219 (2008).

30 NCIB. dbSNP short genetic variations. www.ncbi.nlm.nih.gov/SNP/

31 Ensembl. www.ensembl.org/index.html

32 Hitzl M, Schaeffeler E, Hocher B et al. Variable expression of P-glycoprotein in the human placenta and its association with mutations of the multidrug resistance 1 gene (MDRI, ABCB1). Pharmacogenetics. 14(5), 309-318 (2004).

33 Molsa M, Heikkinen T, Hakkola J et al. Functional role of P-glycoprotein in the human blood-placental barrier. Clin. Pharmacol. Ther. 78(2), 123-131 (2005).

34 Rahi M, Heikkinen T, Härtter S et al. Placental transfer of quetiapine in relation to P-glycoprotein activity. J. Psychopharmacol. 21(7), 751-756 (2007).

35 Hemauer SJ, Nanovskaya TN, Abdel-Rahman SZ, Patrikeeva SL, Hankins GDV, Ahmed MS. Modulation of human placental P-glycoprotein expression and activity by MDR1 gene polymorphisms. Biochem. Pharmacol. 79(6), 921-925 (2010).

36 Noordam R, Aarts N, Hofman A, van Schaik RHN, Stricker BH, Visser LE. Association between genetic variation in the $A B C B 1$ gene and switching, discontinuation, and dosage of antidepressant therapy: results from the Rotterdam Study. J. Clin. Psychopharmacol. 33(4), 546-550 (2013).

37 Kato M, Fukuda T, Serretti A et al. ABCB1 (MDRI) gene polymorphisms are associated with the clinical response to paroxetine in patients with major depressive disorder. Prog. Neuropsychopharmacol. Biol. Psychiatry 32(2), 398-404 (2008).

38 Nikisch G, Eap CB, Baumann P. Citalopram enantiomers in plasma and cerebrospinal fluid of $A B C B 1$ genotyped depressive patients and clinical response: a pilot study. Pharmacol. Res. 58(5-6), 344-347 (2008).

39 Lin KM, Chiu YF, Tsai IJ et al. ABCB1 gene polymorphisms are associated with the severity of major depressive disorder and its response to escitalopram treatment. Pharmacogenet. Genomics 21(4), 163-170 (2011).

40 Singh AB, Bousman CA, Ng CH, Byron K, Berk M. $A B C B 1$ polymorphism predicts escitalopram dose needed for remission in major depression. Transl. Psychiatry 2, e198 (2012).

41 Fukui N, Suzuki Y, Sawamura K et al. Dose-dependent effects of the $3435 \mathrm{C}>\mathrm{T}$ genotype of $A B C B 1$ gene on the steady-state plasma concentration of fluvoxamine in psychiatric patients. Ther. Drug Monit. 29(2), 185-189 (2007).

42 Obermann-Borst SA, Isaacs A, Younes Z et al. General maternal medication use, folic acid, the MDR1 C3435T polymorphism, and the risk of a child with a congenital heart defect. Am. J. Obstet. Gynecol. 204(3), 236.e1-8 (2011).

43 Bliek BJB, van Schaik RHN, van der Heiden IP et al. Maternal medication use, carriership of the ABCB1 3435C $>\mathrm{T}$ polymorphism and the risk of a child with cleft lip with or without cleft palate. Am. J. Med. Genet. A 149A(10), 2088-2092 (2009).

44 Wang C, Zhou K, Xie L et al. Maternal medication use, fetal $3435 \mathrm{C}>\mathrm{T}$ polymorphism of the $A B C B 1$ gene, and risk of isolated septal defects in a Han Chinese population. Pediatr. Cardiol. 35, 1132-1141 (2014).

45 Kato M, Fukuda T, Wakeno M et al. Effects of the serotonin type $2 \mathrm{~A}, 3 \mathrm{~A}$ and $3 \mathrm{~B}$ receptor and the serotonin transporter genes on paroxetine and fluvoxamine efficacy and adverse drug reactions in depressed Japanese patients. Neuropsychobiology 53, 186-195 (2006).

46 Lee SH, Choi TK, Lee E et al. Serotonin transporter gene polymorphism associated with short-term treatment response to venlafaxine. Neuropsychobiology 62(3), 198-206 (2010).

47 Hu X-Z, Rush AJ, Charney D et al. Association between a functional serotonin transporter promoter polymorphism and citalopram treatment in adult outpatients with major depression. Arch. Gen. Psychiatry 64(7), 783-792 (2007).

48 Murphy GM Jr, Hollander SB, Rodrigues HE, Kremer C, Schatzberg AF. Effects of the serotonin transporter gene promoter polymorphism on mirtazapine and paroxetine efficacy and adverse events in geriatric major depression. Arch. Gen. Psychiatry 61(11), 1163-1169 (2004).

49 Staeker J, Leucht S, Laika B, Steimer W. Polymorphisms in serotonergic pathways influence the outcome of antidepressant therapy in psychiatric inpatients. Genet. Test. Mol. Biomarkers 18(1), 20-31 (2014).

50 Bottalico B, Pilka R, Larsson I, Casslen B, Marsal K, Hansson SR. Plasma membrane and vesicular monoamine transporters in normal endometrium and early pregnancy decidua. Mol. Hum. Reprod. 9(7), 389-394 (2003). 
51 Sugai T, Suzuki Y, Sawamura K, Fukui N, Inoue $Y$, Someya T. The effect of 5-hydroxytryptamine $3 \mathrm{~A}$ and $3 \mathrm{~B}$ receptor genes on nausea induced by paroxetine. Pharmacogenomics J. 6(5), 351-356 (2006).

52 Bonnin A, Levitt P. Fetal, maternal, and placental sources of serotonin and new implications for developmental programming of the brain. Neuroscience 197, 1-7 (2011).

53 Hobbs CA, Cleves MA, Karim MA, Zhao W, MacLeod SL. Maternal folate-related gene environment interactions and congenital heart defects. Obstet. Gynecol. 116, 316-322 (2010).

54 Hobbs CA, Cleves MA, Macleod SL et al. Conotruncal heart defects and common variants in maternal and fetal genes in folate, homocysteine, and transsulfuration pathways. Birth Defects Res. A Clin. Mol. Teratol. 100(2), 116-126 (2014).

55 Tang X, Nick TG, Cleves MA et al. Maternal obesity and tobacco use modify the impact of genetic variants on the occurrence of conotruncal heart defects. PLoS ONE. 9(10), e108903 (2014).

56 Tang X, Hobbs CA, Cleves MA et al. Genetic variation affects congenital heart defect susceptibility in offspring exposed to maternal tobacco use. Birth Defects Res. A Clin. Mol. Teratol. 103(10), 834-842 (2015).

57 Wang LY, Lee WC. Population stratification bias in the case-only study for gene-environment interactions. Am. J. Epidemiol. 168(2), 197-201 (2008).

58 Haas DM, D’Alton M. Pharmacogenetics and other reasons why drugs can fail in pregnancy: higher dose or different drug? Obstet. Gynecol. 120(5), 1176-1179 (2012).

59 Haas DM. Obstetric therapeutics-how pharmacogenetics may inform drug therapy for pregnant women in the future. Obstet. Gynecol. Surv. 68(9), 650-654 (2013).

60 Quinney SK, Patil AS, Flockhart DA. Is personalized medicine achievable in obstetrics? Semin. Perinatol. 38(8), 534-540 (2014).

61 Dorfman EH, Cheng EY, Hebert MF, Thummel KE, Burke W. Prenatal pharmacogenomics: a promising area for research. Pharmacogenomics J. 16(4) 303-304 (2016).

$62 \mathrm{Li} \mathrm{M}, \mathrm{Li}$ J, Wei C et al. A three-way interaction among maternal and fetal variants contributing to congenital heart defects. Ann. Hum. Genet. 80(1), 20-31 (2016). 